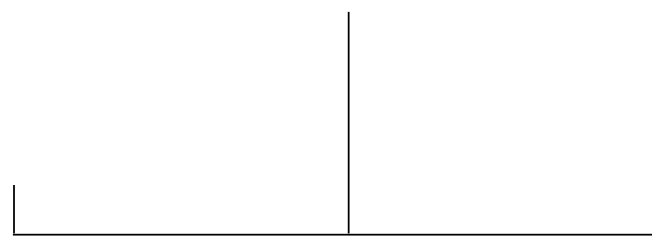

Rev. Latinoam. Psicopat. Fund., São Paulo, v. 15, n. 3, p. 512-523, setembro 2012

\title{
Destinos do método clínico na contemporaneidade*
}

Ana Maria Rudge

\begin{abstract}
O método experimental como garantia de cientificidade é abordado, assim como seu peso e idealização na ideologia cientificista atual. Destaca-se que o método clínico se distingue epistemologicamente do método experimental, e que a ambição de considerá-lo como ciência é equivocada. A psicanálise é tomada como um exemplo, visto que as tentativas de torcê-la de forma a que algum simulacro de teste empírico de sua validade seja possível nunca esmoreceram, apesar de Freud ter dito claramente que seu campo epistemológico era incompatível com isto, e que o método psicanalítico é irredutivel à testabilidade, pois é uma medida terapêutica que não visa provar coisa alguma, mas alterar algo. Sendo ao mesmo tempo um tratamento e um método de investigação, o que a psicanálise visa é minorar o sofrimento neurótico e a reiteração nos caminhos que levam ao pior. Não só a psicanálise, mas toda forma de clínica requer a escuta e a atenção ao que é inevitavelmente singular, o que é um trabalho de Eros, e que vai contra a tendência atual à objetificação das formas de diagnóstico e aos protocolos de tratamento.
\end{abstract}

Palavras-chave: Clínica, epistemologia, psicanálise, ciência

* Este artigo é parte do projeto de pesquisa sobre "O método clínico" coordenado pelo Prof. Dr. Manoel Tosta Berlinck e financiado pelo Conselho Nacional de Desenvolvimento Científico e Tecnológico - CNPq (Brasília, DF, Br) - protocolo 4550688130875149 . 


\section{ARTIGOS}

O que é o método clínico, o curvar-se sobre alguém para curá-lo? O termo klinikós aparece pela primeira vez em escritos de Galeno (séc. II d.C.), sobre os médicos que visitavam os doentes em seus leitos (Durling, 1993). O método clínico tem como peculiaridade o esforço de diagnóstico e tratamento de um determinado sujeito, seja o profissional um médico, um psiquiatra, um psicólogo ou um psicanalista. Mas não desfruta de um lugar inquestionável e valorizado na atualidade, se é que já desfrutou. Alguns se perguntam: existe o método clínico? (Dupuy, 2000). Quando afirmada sua existência, geralmente sua legitimidade é defendida com base na ideia de que ele seria a aplicação do método científico na prática diagnóstica e terapêutica, o que redunda em atrelar sua dignidade àquela que se confere à ciência. Assim, a questão de como caracterizar o método clínico em sua especificidade, não é supérflua, e se articula necessariamente a uma avaliação de quais são suas relações com a ciência, ou com o que se costuma conceituar como sendo ciência.

O prestígio do método experimental como garantia da cientificidade de um campo de saber é conhecido. Galileu, o responsável pela ruptura constituída pela revolução científica moderna, introduz o teste experimental como condição necessária para avaliar o valor de verdade das hipóteses. O experimento constitui o diálogo da razão com a realidade. Inicialmente a razão constrói um modelo hipotético dedutivo, e posteriormente formula à natureza perguntas, a que esta responderá em termos quantitativos. Galileu considera que as hipóteses são apriorísticas, já Newton oferece uma interpretação mais indutivista do que seja o método científico, considerando que as hipóteses físicas são retiradas das experiências pela indução (Köche, 1997, p. 55). 
O século XX traz, com o Círculo de Viena, o projeto de unificação do campo das ciências, e a busca de uma linguagem universal da ciência, partindo do princípio que a ciência parte de induções. A proposta de Carnap, um dos principais representantes do chamado positivismo lógico, é que esta linguagem é a linguagem coisa, ou linguagem fisicalista: sentenças que têm a forma de uma descrição em termos quantitativos: Em tal espaço-tempo-lugar a temperatura é tantos graus.

As proposições com sentido, fonte de conhecimento, são ou as analíticas, baseadas na pura lógica, ou as proposições verificáveis empiricamente. Quanto a estas, o seu sentido é identificado ao método empírico de sua verificação. Só elas podem ser proposições científicas, por serem legítimas afirmativas factuais em oposição às proposições metafísicas, vazias de sentido. Não existe conhecimento sintético a priori, a experiência é o único juiz das teorias científicas. É por meio dela que poderemos concluir que uma proposição é verdadeira ou falsa, e que, portanto, tem sentido. O princípio da verificabilidade preconiza que só saberemos o sentido da proposição, se soubermos em que condições determinar se é verdadeira ou falsa.

Essa teoria do sentido como verificabilidade foi criticada por Karl Popper. Popper recusa a indução como sendo o método da investigação científica, e propõe a falsificabilidade como o critério de demarcação entre o que é científico e o que não é. Existe uma assimetria entre verificação e falsificação. Não se pode, logicamente, verificar de forma conclusiva uma proposição universal por meio da experiência, mas pode-se demonstrá-la falsa por um evento que a contradiga. Portanto, uma teoria só pode ser considerada científica se permitir que dela se derivem predições arriscadas ou improváveis, que possam ser demonstradas falsas por algum evento. Testar uma teoria é uma tentativa de refutá-la ou prová-la falsa. A brilhante demonstração crítica de Popper não minora o fato de que ele compartilha com o empirismo lógico a convicção de que existe uma unidade do método científico, e que este se identifica com o que cada um considera que, na experiência das ciências da natureza, provou-se eficaz, e o método experimental é central na definição do que seja científico.

Desta forma, sua posição quanto à psicanálise não deixa margens à dúvida. A psicanálise, assim como a metafísica, não é falsificável, não se presta à elaboração de previsões testáveis que possam refutá-la de forma conclusiva, e, portanto, não é ciência.

A idealização da ciência dentro deste modelo hipotético dedutivo e experimental cruza a modernidade e ainda está fortemente instalada em nossos dias de hoje, e a posição de Freud em relação a ele é geralmente simplificada ou mal-interpretada. Curiosamente, apesar do seu propalado positivismo, o criador da psicanálise se recusa a levar em conta a crítica tão permanentemente 
sustentada em relação à psicanálise de que ela não seria científica e não passaria de uma fantasia, visto que suas descobertas não seriam passíveis de verificação ou de falsificação por meio do método experimental.

A psicanálise é um campo que se construiu a partir da intervenção clínica na neurose. Freud jamais desconheceu que essa característica histórica e epistemológica da psicanálise a afastava de qualquer cânone que pudesse regular as ciências naturais, assim como a desqualificava perante os ideais positivistas. $\mathrm{O}$ roteiro de sua investigação o alheava irremediavelmente desta tradição, e ele não tinha dúvidas sobre isso. Há uma afirmação, feita ainda em 1909, na qual se desobriga a verificar ou falsificar sua teoria, defendendo a especificidade de sua construção. Diz ele: "A psicanálise não é uma investigação científica imparcial, mas uma medida terapêutica. Sua essência não é provar nada, mas meramente alterar algo" (p. 104). O método clínico é o que diferencia irredutivelmente, pode-se concluir, a psicanálise do modelo da ciência da natureza. Além de ser uma intervenção clínica, a psicanálise é um método de investigação, mas de cunho indutivo.

Em defesa dessa especificidade, Horus Vital Brazil insistia em que a psicanálise é uma prática teorizada. Por outro viés, mas na mesma direção, Miller (1981) defenderá que a psicanálise não é teoria do inconsciente, mas sim uma teoria da estrutura da situação psicanalítica.

Esse claro reconhecimento da especificidade da psicanálise e de sua natural incompatibilidade com o método experimental tem sido consistentemente desconsiderado por várias gerações de psicanalistas, que neste ponto não seguiram a inspiração freudiana, já que este não demonstrou qualquer interesse pela verificação experimental das hipóteses psicanalíticas. Quando, em 1934, Saul Rosenzweig enviou a Freud sugestões de estudos experimentais que poderiam contribuir para o estudo do recalque, eis a resposta que dele recebeu:

Meu caro Senhor, examinei seus estudos experimentais para a verificação das hipóteses psicanalíticas com interesse. Não posso valorizar demasiado essas confirmações, porque as observações em que essas asserções se apoiam fazemnas independentes de verificação experimental. (Shakow \& Rapaport, 1964, p. 129)

Foi a fascinação pelo modelo da lei científica de alcance universal, verificável ou falsificável experimentalmente, que esteve sem dúvida em jogo como um ideal subjacente a várias das propostas da psicologia do ego em relação à psicanálise, inclusive na própria definição do objeto da psicanálise como sendo o comportamento humano. O desejo de aproximar a interpretação psicanalítica de um teste experimental foi fartamente expresso em artigos como o de Wisdom (1967), “Testando uma interpretação dentro da sessão", onde uma das indagações 
que se pode ler é: "como uma hipótese clínica como o Édipo pode ser testada?" (p. 44). A ideia de que uma interpretação pode ser refutável, no sentido experimental que lhe dá Popper, é acalentada.

É como se, nessa proposta, Wisdom se mostrasse mais realista que o rei. $\mathrm{Na}$ verdade, Popper (1969) não considera que se possa fazer predições falsificáveis no campo das ciências humanas e sociais. Sua crítica ao historicista é a de que este toma os casos de profecias das ciências naturais e tenta inadequadamente transpô-los ao campo da história e das sociedades. Entretanto, nem mesmo no caso das ciências da natureza, essas predições claras são a norma; elas só se aplicam a sistemas isolados, estacionários e repetitivos. Ora, "o fato que predigamos eclipses não nos fornece uma razão válida para esperar que possamos prever revoluções" (p. 340).

Os acontecimentos da história são únicos, mutáveis, não se repetem; a ideia de predição, nesse campo, é falaciosa. Se predições exatas não podem ser feitas na história humana, já que ela é constituída por eventos singulares, não é de admirar que o campo da psicanálise também não se preste a isso.

As tentativas de adequar a psicanálise aos critérios de cientificidade das ciências da natureza, entretanto, nos acompanham até os dias de hoje. Tomemos como exemplo o esforço de pesquisa que vem sendo despendido no âmbito da IPA dentro da convicção de que "novas estratégias de pesquisa são necessárias para mostrar que as mudanças de personalidade são tanto mensuráveis quanto relevantes clinicamente. Estudos sobre a eficácia usando modelos randomizados controlados são necessários" (Bateman e Fonagy, 2000, p. 143).

Essa ideologia toma agora novo alento, com a oportunidade de apoiar o prestígio da psicanálise nas neurociências e em sua cientificidade. Marie-Claude Thomas (2011) nos mostra como o livro de Michel Pommier, Como as neurociências demonstram a psicanálise (2004/2007), representa na verdade uma tendência reducionista a ceder às neurociências o campo da psicanálise, tendência que está em expansão nos dias de hoje, e que busca tomar de empréstimo o prestígio "científico" das neurociências.

Voltando à lúcida afirmação freudiana de que a psicanálise não é uma investigação científica imparcial, mas uma medida terapêutica (Freud, 1909, p. 104), afirmamos que nesta assertiva é a vocação clínica da psicanálise que está sendo colocada em destaque, e que esta vocação a afasta irredutivelmente do método experimental e da ciência, pelo menos tal como é concebida pelo positivismo.

1. New research strategies are needed to show that personality change is both measurable and clinically meaningful. Effectiveness studies using randomised controlled designs are required. 
Isto não é uma afirmativa que se limite à psicanálise, mas à clínica de modo geral. Como observa Serpa (2003), Canguilhem reconhece que a medicina é "uma técnica ou uma arte situada na confluência de várias ciências, mais do que uma ciência propriamente dita" (Canguilhem, 1966, p. 16). Embora mantenha laços com a ciência, seu compromisso fundamental é com a clínica e a terapêutica, e por esta razão ela não pode ser "inteiramente reduzida ao simples conhecimento" (ibid.).

A psicanálise não se adequa ao modelo médico, como se sabe e como Freud fez questão de enfatizar, e sua especificidade não pode ser desconsiderada. Entretanto, medicina e psicanálise são ambas afeitas ao método clínico, e isto significa que não podem ser reduzidas ao mero conhecimento científico, uma vez que o indivíduo como um todo, sua singularidade, e as contingências ligadas à sua história têm de ser levados em conta de forma central na conduta terapêutica.

É aqui que o paradigma indiciário, ao qual Carlo Ginzburg (1989) dedicou surpreendente estudo, e que supõe estar presente como inspiração na própria construção do campo psicanalítico por Freud, tem a nos esclarecer. Surpreendente porque articula campos de saber bastante díspares, como medicina, psicanálise, historiografia e arte, Ginzburg circunscreve um método de conhecimento que seria operativo em todos esses campos, e que, em oposição ao método científico hipotético dedutivo, se volta para a leitura e interpretação de sinais, indícios, detalhes aparentemente sem importância, abrindo espaço para a consideração do subjetivo, do particular, e do contingente.

Este modelo teria tido sua origem ao final do século XIX em forte associação com a semiologia médica, que chega ao diagnóstico pela atenção a sintomas. Ginzburg manifesta a esperança de que, ao levar esse modelo em conta, possamos "sair dos incômodos da contraposição entre 'racionalismo' e 'irracionalismo' (p. 143). Ginzburg não entra em maiores detalhes sobre esta esperança que manifesta, este voto, mas ele não parece difícil de interpretar ao considerarmos que o autor afirma que as disciplinas indiciárias não cabem de forma alguma nos critérios de cientificidade do paradigma galileano, para o qual o singular não tem lugar. Não é por outro motivo que Lacan afirma que a ciência moderna foraclui o sujeito.

O prestígio da ciência moderna tem o valor de uma ideologia. O que tem o rótulo de científico merece toda a confiança, já que a ciência costuma ser tomada em alta conta, e ser quase confundida com a racionalidade.

A proposta de Ginsberg é pensar - fora deste modelo hegemônico de ciência, na qual a generalização é o parâmetro básico - o caso das disciplinas eminentemente qualitativas que têm por objeto casos, situações e documentos individuais, e que não podem, justamente por esta razão, encontrar senão 
resultados nos quais uma "margem ineliminável de casualidade" está sempre presente, é inevitável” (p. 156).

As relações do método indiciário com a psicanálise são destacadas por Ginzburg. Ele deriva dos escritos do médico italiano Giovanni Morelli que, sob o pseudônimo de Ivan Larmolieff, propunha um método para distinguir pinturas originais de cópias e falsificações. Em vez de se fixar aos aspectos mais importantes da obra, que são mais facilmente imitadas, recomendava a atenção em pequenos detalhes.

Em texto de 1914, Freud relata ter conhecido o método morelliano pelos ensaios por ele publicados em 1874 e 1876 sob pseudônimo, muito antes do surgimento da psicanálise. Afirma também que o método de Morelli é muito semelhante à técnica psicanalítica, que atenta para coisas tidas como pouco importantes, pouco notadas, restos que aos outros pesquisadores não interessavam, como lapsos e sonhos, e que Freud tomou como especialmente reveladores. O apontamento para o sujeito é claro no caso de Morelli: o que remeterá ao verdadeiro criador da obra são os pequenos indícios e detalhes.

O método indiciário tal como se pode pensá-lo em operação na psicanálise, também visaria o sujeito em sua singularidade, constituído pelos caminhos de sua história, permeados pelo acaso.

Com Freud, o sintoma não aponta para determinado processo mórbido, mas para o sujeito como barrado e sua sexualidade. Os sintomas psicanalíticos estão ancorados na linguagem, expressando fragmentos esquecidos de história pessoal, constituindo às vezes uma forma disfarçada de satisfação pulsional, além de se organizarem na transferência, sensíveis às peripécias da interlocução com o analista.

Ginzburg levanta a questão de dois paradigmas a escolher: a busca do universal, idealmente em linguagem matemática, que foi a via da ciência natural, ou a busca de elaborar um paradigma novo, voltado para o conhecimento do individual, no qual o método clínico se abrigaria.

Científico? Parece-me desnecessário assim definir o último paradigma. Há uma racionalidade que escapa ao modelo hegemônico da ciência da natureza, e sua dignidade é proporcional a sua relevância para o homem, e não a seu rigor. Ao tomarmos a referência à singularidade como fundamental, o campo da história, da política, da psicanálise, da psicopatologia, se preenche de certa indeterminação que não é evitável, e a busca de rigor só poderia deformar esses campos. É o que se pode concluir da opinião de Ginzburg de que "a orientação quantitativa e antiantropocêntrica das ciências da natureza a partir de Galileu colocou as ciências humanas num desagradável dilema: ou assumir um estatuto científico frágil para chegar a resultados relevantes, ou assumir um estatuto científico forte para chegar a resultados de pouca relevância” (p. 178). 
$\mathrm{Na}$ escolha entre esses dois paradigmas, aparentemente o prestígio das ciências da natureza, muitas vezes, se sobrepõe ao interesse de levar em conta e escutar realmente o sujeito nos campos em que o foco é a clínica, o debruçarse sobre, e o atendimento terapêutico. Ginzburg faz uma interessante observação, que aqui privilegiamos: a tendência a apagar os traços individuais de um objeto é diretamente proporcional à distância emocional do observador.

Se o método indiciário não é irracional, se Freud traz uma nova racionalidade ao que se mantinha no campo do irracional - como sintomas neuróticos, sonhos e lapsos - não se pode entender os sintomas objetivando-os, mas o sujeito deles precisa falar, tanto de seu sofrimento como de sua experiência.

Desse ponto de vista, o psicopatológico solicita "um discurso mitopoiético epopeico, que é terapêutico porque produz experiência" (Berlinck, 2000). Definindo-se a psicopatologia fundamental como a posição de escuta do discurso do sujeito do seu pathos, transformando-se com essa narrativa numa experiência partilhada, temos que concordar com a ideia de Platão de que a medicina (e aqui a clínica em geral deve ser incluída) é a arte que se ocupa dos fenômenos do amor, e o psicopatólogo, assim como o médico, cuida do Eros doente através do amor.

Como um importante campo da Psicopatologia Fundamental, a psicanálise valorizou o amor de transferência como motor necessário do tratamento, amor que certamente inclui o analista, na medida em que este não se imponha uma distância afetiva do seu cliente, de molde a proteger seu próprio narcisismo, e se mascare sob uma atitude pseudocientífica.

Assim, chegamos a caracterizar a clínica como pertencente ao paradigma indiciário, mas, ao mesmo tempo, como apresentando uma especificidade dentro deste paradigma. A vocação terapêutica que está presente nas artes da medicina e da psicanálise não se encontra, por exemplo, na busca de identificação do verdadeiro autor de um quadro, da individualidade artística, ou na identificação de um criminoso por meio de pistas por ele deixadas, como na arte de Sherlock Holmes. Estes casos convocam formas de saber cujas regras "não se prestam a ser formalizadas nem ditas" (Ginzburg, 1989, p. 178), mas que não deixam de caber numa definição de racionalidade.

Com a clínica, há algo mais em questão, um importante aspecto que não está incluído na conceituação do paradigma indiciário. Eros como disposição à escuta, a fazer laços e propiciar a simbolização e o desejo. É esse o elemento que está fazendo falta na clínica na contemporaneidade, visto que o tempo para escutar está sempre mais curto, o diagnóstico, tanto na medicina quanto na psiquiatria, é baseado em alguns traços específicos, sintomas ou exames objetivos, e se recorre a protocolos para conduzir os tratamentos. A psicanálise, como prática que faz resistência a essa tendência, vem recebendo sempre maiores ataques. 


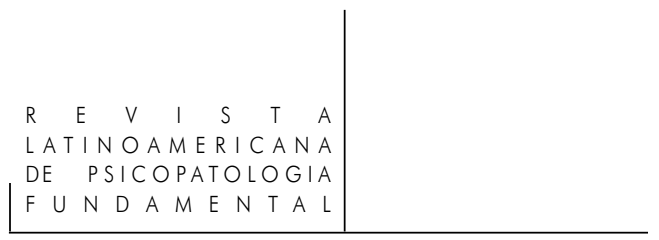

\section{Referências}

Bateman, A. W.; Fonagy, P. Effectiveness of psychotherapeutic treatment of personality disorder. The British Journal of Psychiatry, n. 177, p. 138-43, 2000.

Beruinck, M. Psicopatologia Fundamental. São Paulo: Escuta, 2000.

CANGuilhem, G. (1966). O normal e o patológico. Rio de Janeiro: Forense Universitária, 1982.

Dupuy, F. I. El método clínico: muerte y resurrección. Revista Cubana Edc Med Super, v. 14, n. 2, p. 109-27, 2000.

DurLING, R.J. A Dictionary of Medical Terms in Galen. Leiden: EJ Brill, 1993. p. 205.

FreUd, S. (1909). Analysis of a phobia in a five-year boy. In: The Standard Edition of the Complete Psychological Works of Sigmund Freud (SE). London: Hogarth Press, 1975. v. X, p. 5-148.

Freud, S. (1914). The Moses of Michelangelo. In: The Standard Edition of the Complete Psychological Works of Sigmund Freud. London: Hogarth Press, 1975. v. XIII, p. 211-36.

GinZBurg, C. Sinais: raízes de um paradigma indiciário. In: Mitos, emblemas, sinais: morfologia e história. São Paulo: Companhia das Letras, 1989.

Köche, J.C. Fundamentos de metodologia científica. Petrópolis, RJ: Vozes, 1997.

Miller, J-A. Jacques Lacan 1901-1981. Ornicar? n. 24, p. 35-46, 9 de setembro de 1981.

SERPA, O. D. Indivíduo, organismo e doença: a atualidade de "O normal e o patológico" de Georges Canguilhem. Psicologia Clínica, Rio de Janeiro, v. 15, n. 1, p. 121-35, 2003.

Shakow, D.; RAPAPORT, D. The Influence of Freud on American Psychology. Psychological Issues, Mono. 13, 1964.

WisDom, J.O. Testing an interpretation within a section. International Journal of Psycho-Analysis, n. 48, p. 44-52, 1967.

\section{Resumos}

(Prospects for the Clinical Method Today)

The experimental method as a guarantee of scientificity is discussed here, together with its idealization in today's scientificist ideology. The author argues that the clinical method is epistemologically distinct from the experimental method, and attempts at 


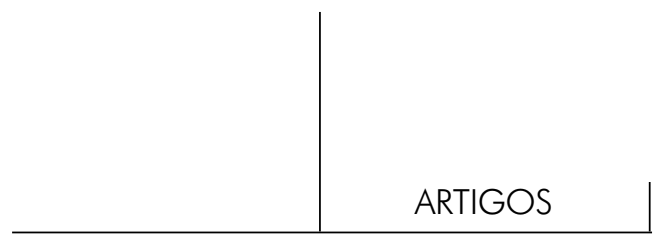

considering the former as science is mistaken. Psychoanalysis is taken as an example, since some psychoanalysts have continued to try to create imitations of experimental tests in order to validate their clinical methods. This has occurred in spite of Freud, who clearly stated that psychoanalysis was epistemologically incompatible with experimental science, and that the psychoanalytic method cannot be submitted to tests because it is a therapeutic measure whose purpose is to reduce neurotic suffering and to redirect from paths that only worsen things. Not only psychoanalysis but every form of clinical work requires listening and attention to what is inevitably singular, which is the work of Eros, the navigates against the wind of today's trends toward the objectification of the forms of diagnosis and of the use of treatment protocols.

Key words: Clinic, epistemology, psychoanalysis, science

(Destins de la méthode clinique dans la contemporanéité)

Cet article porte sur la méthode expérimentale comme garantie de scientificité, ainsi que sur son poids et son idéalisation dans l'idéologie courante du scientisme. Nous affirmons que la méthode clinique est épistémologiquement diverse de la méthode expérimentale et que de vouloir la considérer comme science est une idée équivoque. Nous prenons la psychanalyse comme exemple, étant donné que les tentatives de l'adultérer pour pouvoir la valider à travers des tests empiriques simulacres persévèrent, malgré le fait que Freud avait clairement déclaré que son champ épistémologique était incompatible dans ce sens et que la méthode psychanalytique ne peut pas être testée, étant donné qu'il s'agit d'une mesure thérapeutique qui ne cherche pas à prouver quelque chose, mais à changer quelque chose. Non seulement un traitement, mais aussi une méthode de recherche, la psychanalyse a comme but de réduire la souffrance du névrosé, ainsi que la réitération sur les chemins qui mènent au pire. Non seulement la psychanalyse, mais toute forme de clinique exige l'écoute et l'attention envers ce qui est inévitablement singulier. Il s'agit en effet d'un travail d'Éros qui va contre la tendance courante de l'objectification des formes du diagnostic et des protocoles de traitement.

Mots clés: Clinique, épistémologie, psychanalyse, science

(Los destinos del método clínico en la contemporaneidad)

El método experimental es examinado como garantía de cientificismo, así como su peso e idealización en la actual ideología cientificista. Se destaca que el método clínico desde el punto de vista epistemológico es distinto del método experimental, y que la ambición de considerarlo como científico es equivocada. Se toma al psicoanálisis como un ejemplo, porque los intentos en retorcerla para que una imitación de prueba empírica de su validez sea posible nunca han sido abandonados, a pesar de Freud haber expresado claramente que su campo epistemológico era incompatible con esto, y que el método psicoanalítico es irreductible al testeo, pues es una medida terapéutica que no busca demostrar nada, sino modificar algo. Siendo al mismo tiempo un tratamiento y un méto-

Rev. Latinoam. Psicopat. Fund., São Paulo, v. 15, n. 3, p. 512-523, setembro 2012 
do de investigación, lo que el psicoanálisis visa es disminuir el sufrimiento neurótico y la reiteración en los caminos que conducen a lo peor. No sólo el psicoanálisis como también la clínica en general, requiere una escucha y atención a lo que es singular, lo cual es una obra de Eros, y que va contra la tendencia actual de establecer objetivos ( será este o sentido de objetificaçión? Ou se trata de transformar o indivíduo ou sujeito em coisas? Então seria cosificación) en las formas de diagnóstico y a los protocolos de tratamiento.

Palabras clave: Clínica, epistemologia, psicoanálisis, ciencia

\section{(Ziele der klinischen Methode in der Gegenwart)}

Hier wird die experimentelle Methode als Garantie für die Wissenschaftlichkeit und ihre Bedeutung und Idealisierung in der aktuellen wissenschaftlichen Ideologie behandelt. Es wird hervorgehoben, dass die klinische Methode sich epistemologisch von der experimentellen Methode unterscheidet, und dass die Absicht, sie als Wissenschaft zu bezeichnen, ein Irrtum ist. Die Psychoanalyse wird als Beispiel genommen, da die Versuche sie so zu drehen, dass irgendein Trugbild eines empirischen Tests ihrer Gültigkeit mögliche wäre, nie aufgegeben wurden. Und dies, obwohl Freud eindeutig gesagt hat, dass sein e epistemologisches Feld nicht damit in Einklang gebracht werden kann, und dass diese psychoanalytische Methode unbeugsam gegenüber der Prüfbarkeit ist. Denn sie ist eine therapeutische Maßnahme, die nicht den Anspruch hat, etwas zu beweisen, sondern etwas zu verändern. Die Psychoanalyse ist gleichzeitig eine Behandlungsmethode und eine Untersuchungsmethode, die darauf abzielt, das neurotische Leiden und die Wiederholung der Wege, die zum Schlimmsten führen, zu verringern. Nicht nur die Psychoanalyse, sondern jegliche Form der Klinik setzt das Hören und die Aufmerksamkeit auf das unvermeidbare Einmalige voraus. Dies ist eine Aufgabe des Eros und läuft in entgegengesetzte Richtung wie die aktuelle Tendenz der Verdinglichung der Diagnoseformen und der Behandlungsprotokolle.

Schlüsselwörter: Klinik, Epistemologie, Psychoanalyse, Wissenschaft

Citação/Citation: Rudge, A.M. Destinos do método clínico na contemporaneidade. Revista Latinoamericana de Psicopatologia Fundamental, São Paulo, v. 15, n. 3, p. 512-523, set.2012.

Editor do artigo/Editor: Prof. Dr. Manoel Tosta Berlinck

Recebido/Received: 16.11.2011 / 11.16.2011 Aceito/Accepted: 20.2.2012 / 2.20.2012

Copyright: () 2009 Associação Universitária de Pesquisa em Psicopatologia Fundamental/ University Association for Research in Fundamental Psychopathology. Este é um artigo de livre acesso, que permite uso irrestrito, distribuição e reprodução em qualquer meio, desde que o autor e a fonte sejam citados / This is an open-access article, which permits unrestricted use, distribution, and reproduction in any medium, provided the original author and source are credited.

Rev. Latinoam. Psicopat. Fund., São Paulo, v. 15, n. 3, p. 512-523, setembro 2012 


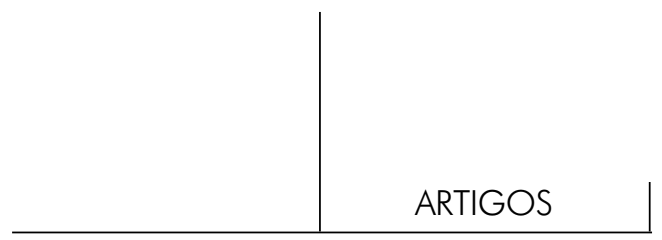

Financiamento/Funding: Esta pesquisa é financiada pelo Conselho Nacional de Desenvolvimento Científico e Tecnológico - CNPq / This research is funded by the National Counsel of Technological and Scientific Development - CNPq.

Conflito de interesses/Conflict of interest: A autora declara que não há conflito de interesses / The author declares that has no conflict of interest.

\section{Ana Maria Rudge}

Professora Associada do Departamento de Psicologia da Pontifícia Universidade Católica do Rio de Janeiro - PUC-Rio (Rio de Janeiro, RJ, Br); Membro Psicanalista da Sociedade de Psicanálise Iracy Doyle (Rio de Janeiro, RJ, Br); Pesquisadora do CNPq (Brasília, DF, Br); Pesquisadora e Membro Fundador da Associação Universitária de Pesquisa em Psicopatologia Fundamental (São Paulo, SP, Br).

Rua Marquês de São Vicente, 225 - Edifício Cardeal Leme, sala 201 - Gávea 22453-900 Rio de Janeiro, RJ, Br

Fone: (21) 3527-1185

e-mail: arudge@ puc-rio.br / ana.rudge@uol.com.br 